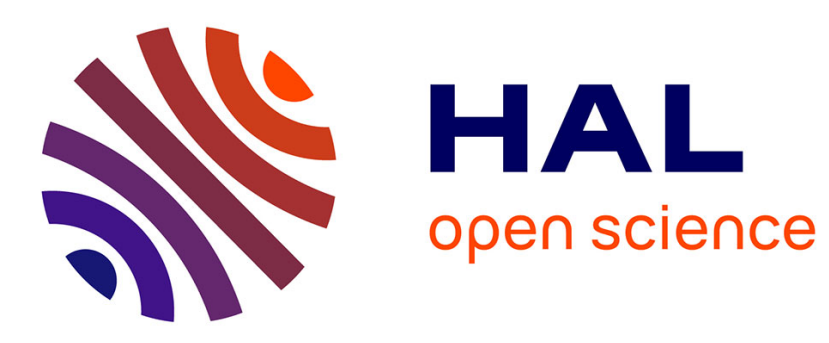

\title{
A Preliminary Overview of Ramp-Up Management Practices in Crisis Context
}

Doae Riffi Maher, Khaled Medini

\section{To cite this version:}

Doae Riffi Maher, Khaled Medini. A Preliminary Overview of Ramp-Up Management Practices in Crisis Context. APMS 2021: Advances in Production Management Systems. Artificial Intelligence for Sustainable and Resilient Production Systems, Sep 2021, Nantes, France. pp.484-492, 10.1007/9783-030-85874-2_51. emse-03338251

\section{HAL Id: emse-03338251 https://hal-emse.ccsd.cnrs.fr/emse-03338251}

Submitted on 9 Nov 2021

HAL is a multi-disciplinary open access archive for the deposit and dissemination of scientific research documents, whether they are published or not. The documents may come from teaching and research institutions in France or abroad, or from public or private research centers.
L'archive ouverte pluridisciplinaire HAL, est destinée au dépôt et à la diffusion de documents scientifiques de niveau recherche, publiés ou non, émanant des établissements d'enseignement et de recherche français ou étrangers, des laboratoires publics ou privés. 


\title{
An Overview of Ramp-up Management Practices in Crisis Context
}

\author{
Doae Rifii Maher ${ }^{1}$ and Khaled Medini ${ }^{2}$ \\ ${ }^{1}$ Mines Saint-Etienne, F-42023 Saint-Etienne France. doae.riffimaher@etu.emse.fr \\ ${ }^{2}$ Mines Saint-Etienne, Univ Clermont Auvergne, CNRS, UMR 6158 LIMOS, Henri Fayol Institute, F-42023 Saint-Etienne \\ France. khaled.medini@emse.fr
}

\begin{abstract}
Production ramp-up is a key stage in the product life cycle since it can determine whether a product's launch into the market or the increase of production capacity succeeds or fails. Ramp-up as a phase of value creation, begins with the completion of a product's design and ends with the reach of maximum production capacity. In today's world, there is a significant advance in technology but simultaneously there is an increasing uncertainty as we have experienced with the covid-19 crisis. Within this context, the importance of ramp-up or ramp-down management become more than ever evident. Whilst some products like face masks saw their demand increase drastically, some other companies had to shut off their production or switch to manufacture new products like hand sanitizers. Hence, it is critical today to have a successful ramp-up management in order to predict and meet clients' demand in terms of quality and quantity. This paper aims to provide a set of guidelines for ramp-up management considering crisis context. The paper relies on an exploratory research coupling literature analysis and interviews among practitioners. The insights drawn from the literature and from the interviews are expected to provide decision makers with valuable guidance with regard to ramp-up management.
\end{abstract}

Keywords: Ramp-up Management, Agility, Strategy, Industry 4.0, Guidelines.

\section{$1 \quad$ Introduction}

The study of ramp-up or ramp-down in production is an issue that has been around for a long time in manufacturing and service industries. Whether it's the increase in production capacity to meet rising market demand or the introduction of a new product, Ramp-Up as a basic concept is still familiar yet challenging to production managers and even to the company's support functions. However, the technological advances that the world is experiencing today, whether in terms of the techniques used or even the business models of companies, mean that ramp-up today is no longer limited to its classic definition of increasing production capacity. On the contrary, in the context of a pandemic crisis, for example, a good management of ramp-down would be judged by looking at the level of flexibility of the means of production to produce less, or even to completely disrupt the activity of the company or the product delivered. Hence, we can but presume that with the enhancement of Industry 4.0 and the use of technologies it brought about will significantly improve the ramp-up quality, provided that its conduct is carried on in an agile way and in the context of a flexible and resilient production system as well as workforce. Therefore, rampup literature started to receive more attention during the last decade focusing mainly on the conceptualization of the ramp-up phase. This helped lay foundations for further research to improve ramp-up performance mainly from cost and time perspectives. Looking into the scientific literature, there is no obvious answer to agility and resilience challenges. In fact, the current sanitary and climate crises unveiled the need for extending traditional performance perspective in order to integrate agility principles and sustainability objectives in ramp-up management. Further on, the sanitary crisis put forth the need for quick ramp-up or ramp-down in a variety of sectors, whilst most of the research development in this field involves only few sectors such as automotive and microelectronics industry [1].

This paper aims to provide a set of guidelines for ramp-up management considering crisis context. The paper relies on an exploratory research coupling literature analysis and interviews among practitioners. The remainder of the paper is organized as follows, Section 2 provides an overview of ramp-up management concepts. Section 3 reports on ramp-up management challenges in uncertain contexts. Section 3 reports on how the interviews were designed and conducted and discusses the results. The insights drawn from the literature and from the interviews are expected to provide decision makers with valuable guidance with regard to ramp-up management in crisis context. 


\section{State of the art on ramp-up management}

\subsection{Ramp-up phase overview and characteristics}

The ramp-up phase occurs when a new product is introduced in a factory but also when a new process or a new plant starts up [1]. Terwiesch and Yi [2] add that during this phase, the production shifts from development on a small laboratory-like scale into a high-volume-production environment. Hence, the actual aim of production rampup is generally expressed in terms of increasing the volume output from a zero level to a steady state production with a volume output which has been planned for [3]. To well place ramp-up phase in a lifecycle of a product (Figure 1), it is commonly accepted to define ramp-up as the connecting phase between product development and series production [4]. From all the previous definitions, we can see that the definition of ramp-up is strongly connected to the introduction of a new production or production system. However, this general definition can find exceptions to it in the automotive industry for instance. Actually, the specificity of this industry is that the new product introduction projects (aka ramp-up projects) do not always refer to products which are completely new. They can actually concern face-lifting or bringing about changes in existing models [1].

In addition to its temporality feature, the ramp-up phase has some other inherent features such as low initial level of knowledge about the product and the process, low production output, higher cycle time, low production capacity, high demand, high disturbances in process, supply chain or product quality and lack of planning reliability [1] [5]. As a matter of fact, the change management when it comes to the introduction of a new product or process comes along with an urging necessity of learning and training of the workforce. It is then no wonder to see that training and learning are among the most critical factors affecting the production ramp-up both before and after its implementation. The high disturbance observed in production processes and supply chain justifies that supplier inclusion, verification and relations are as well amongst the critical components of the production rampup success [3]. Figure 1 gives a larger insight regarding the critical factors affecting production ramp-up in the pre- and post-phases.

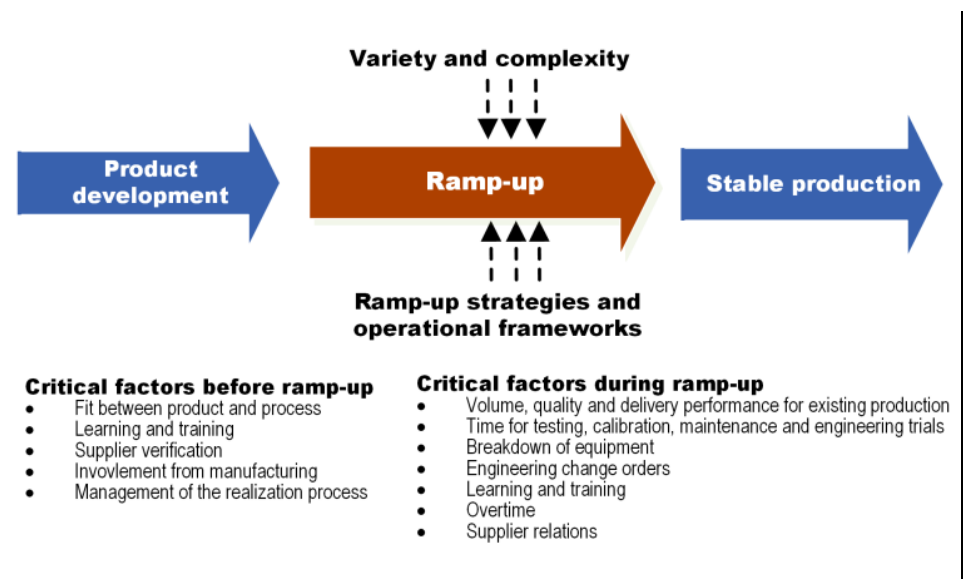

Fig. 1. Ramp-up phase in product life cycle and critical factors during and before production ramp-up. Ramp-up is supported by ramp-up strategies and operational frameworks and challenged by variety and complexity of products and production systems.

\subsection{Ramp-up strategies}

As discussed above, the ramp-up phase has some characteristics which distinguish it from the mature product phase. In fact, the high uncertainty which defines this phase [1] [4] [6] makes the probability of occurrence of discrepancies as well as their variety much higher than for a mature product. Hence, the management techniques that apply for mature products do not have a great performance when it comes to production ramp-up phase. To deal with the peculiarities of ramp-up phase, several strategies can be pursued. Schuh, Desoi, and Tücks [7], suggest three generic ramp-up strategies depending mainly on product variety and induced complexity [1] [3]. The objectives of each of the strategies and the adequate use cases are summarized in Table 1. These strategies provide general insights into how to proceed with ramp-up in a multi-variant context. They do not provide however operational guidance on how to deploy these strategies. In an early study in the automotive industry, Clark \& Fujimoto 
[8] looked deeper into the work force policy as well as the operations pattern during ramp-up. They described various techniques that were used in final assembly for the ramp-up of new products. The strategies consist of a mixture of decisions about how to address the ramp-up with regard to three distinct aspects. These three aspects are ramp-up curve, operation pattern, and policy of the workforce [1] [3] [6]. These choices result in two possible ramp-up strategies of the three aspects combined, "step-by-step" and "shut down". A "Step-by-step" strategy implies stability and control of operating conditions and work assignment. "Shut-down" strategy implies low initial complexity both due to material handling and work force involvement but in the long run task continuity and operation stability will suffer [7].

Table 1. Ramp-up strategies according to Schuh, Desoi, and Tücks [7]

\begin{tabular}{ccc}
\hline Ramp-up strategy & Aims for & Suits \\
\hline Slow motion & $\begin{array}{c}\text { Parallel ramp-up of several variants on a } \\
\text { constant and low volume level until all } \\
\text { processes are verified. }\end{array}$ & $\begin{array}{c}\text { Highly automated pro- } \\
\text { cesses }\end{array}$ \\
& $\begin{array}{c}\text { Ramp-up of all different variants with ac- } \\
\text { cumulative volumes and a gathered } \\
\text { launch of these. Elimination of problems } \\
\text { on an early stage that will not occur. }\end{array}$ & $\begin{array}{c}\text { High product variety and } \\
\text { high logistic capability }\end{array}$ \\
Dedication & $\begin{array}{c}\text { Sequential ramp-up of consecutive vari- } \\
\text { ants with high complexity. }\end{array}$ & High technical complexity \\
\hline
\end{tabular}

In order to assess the efficiency of the ramp-up, several KPIs are considered, which can be categorized into four general classes [1]: cost related (i.e. investments and manpower used to make up capacity loss), quality related (e.g. yield), volume related (e.g. capacity utilization) and time related (e.g. cycle time and time-to-market). While some of the KPIs seem to be significant, there is an issue regarding time related KPIs. Time-to-volume needs to have the exact same level of importance as time-to-market because the imbalance between the two can result in disastrous financial consequences. Furthermore, used KPIs rarely consider the customer point of view, which may be quite harmful for low-volume industries or customized goods.

\section{Case studies}

In this section, we present two concrete examples for ramp-up management. In order to check whether research findings apply to real-world industries, we have interviewed two practitioners from local companies on their rampup management but also regarding their sanitary crisis management, environmental crisis engagement and workforce management. The choice of local companies from two different sectors was with the aim to have the opportunity to compare on a local level, the ramp-up experience of the industrials. It was also an opportunity to understand whether the field of activity and the company size among other factors are determining in the quality of ramp-up management and the resilience in the context of a crisis such as the current covid-19 epidemic. These interviews were conducted by following an interview guide. The questions of this guide were inspired from the scientific literature conclusions seen in Section 2. These questions involve current and past ramp-up management practices, ramp-up challenges for the company, considerations of environmental impact during ramp-up, and covid-19 crisis impact on operational ramp-up management and on employees and workforce.

\subsection{Results from interview 1 - cycling industry}

The first interview was conducted with a local start-up (Company A) that operates in the field of manufacturing cargo bikes. During the interview, the company's director was asked questions as per the interview guide. Generally, the case of this company shows that the crisis does not necessarily have a negative impact on the activity of all companies. The impact is indeed related to the activity field and the type of products that the company offers. In this particular case, the demand for bicycles as a safer alternative in the current sanitary crisis helped boost the enterprise's demand and gave this start-up a great opportunity for growth. Actually, the decision of ramping up the production in this company was rather inspired by the increasing demand of bikes as a more hygienic and safer 
alternative to using shared cars or public transportation in the context of a worldwide pandemic. Ramp-up management practices derived from the interview are structured in a set of guidelines as follows.

- Collaboration among the totality of company departments that are directly or indirectly affected with rampup keeps the motivation and communication running well among the company staff.

- Standardization of the processes is the key for a better learning curve of the employees which can help realize a faster launch of the product in terms of time-to-market. Additionally, standardization helps have a more flexible workforce (since the work to be done does not rely solely on the person in charge of the task but is rather well-explained so that any other teammate or new staff member can learn the job fast).

- Resilience towards unfortunate and unexpected events like the current covid-19 crisis is a key factor when it comes to ramp-up. This can be achieved with a surge-capacity in anticipation of unexpected demand. Resilience is also better achieved with having a surge ramp-up team (with the use of temporary workers or subcontractors).

- Relationship with supply chain actors is crucial when it comes to ramp-up decisions. The collaboration with local supply chain actors can be a great way to overcome shortage in raw materials or difficulties in transportations due to closing borders as we have seen in the context of the Covid-19 crisis. Localised supply chain actors are also another step towards a more eco-friendly and sustainable solution.

- Having a solid business plan justifying the ramp-up decision. The first objective of a company is to generate profit. Consequently, the decision of ramp-up must be justified with the company's financial profit projection. Having a solid business plan helps make sure that the income will outweigh the cost of investment (in machinery acquisition, recruitment, training...).

- Relying on individuals' knowledge rather than establishing standardized processes is a big obstacle that ramp-up management can face. In the case of the company A, this has proven to be a big burden that brakes the ramp-up progress. Within this company, the fact that knowledge is dependent on the experience of the staff makes it very difficult to transmit to new employees. Consequently, this may mean that departure of the experienced member of staff can alter the whole process of the company or even stop its activity.

\subsection{Results from interview 2 - additive manufacturing}

The second interview was conducted with company B which is a local Small/Medium sized enterprise (SME) operating in the field of additive manufacturing (AM). During the interview, an expert from AM R\&D department were asked questions as per the interview guide.

Generally, the interview with Company B supports that the activity field and the level of technology are determining factors in regard to ramp-up management as well as its response to crisis context. In the field of additive manufacturing, especially in the phase of pre-ramp-up, total remote work is possible. Hence, this part of activity of the company is not heavily affected by the covid-19 crisis. During the interview, great emphasis was put on the change management and collaboration between all the stakeholders within the company as well as the various supply chain actors in regard to a successful ramp-up management. Furthermore, the accuracy between the business plan and the progress of ramp-up is one aspect that can measure the performance of ramp-up as it goes. Rampup management practices derived from the interview are structured in a set of guidelines as follows.

- Collaboration among the totality of actors (design office, management, sales, logistics \& purchasing, infrastructure \& buildings, etc.) that are directly or indirectly affected by ramp-up. This means that not only internal stakeholders are concerned but some external actors take part in the ramp-up decision and execution as well.

- Information system is a primordial aspect when it comes to ramp-up management. The collaborative tools make it possible for different actors to share real time data and for the communication to run smoothly as well. Additionally, having a solid and up-to-date information technology within the company makes it easier to tackle teleworking like in covid-19 crisis for instance.

- Resilience towards unfortunate and unexpected events like the current covid-19 crisis is a key factor when it comes to ramp-up. This can be achieved with a surge-capacity in anticipation of unexpected demand. Resilience is also better achieved with having a surge ramp-up team (with the use of temporary workers or subcontractors). Resilience is also better achieved through training on change management. 
- Relationship with supply chain actors is crucial when it comes to ramp-up decisions. Similarly to the first interview, it was seen that the collaboration with local supply chain actors can be a great way to overcome shortage in raw materials or difficulties in transportations.

- Having a solid business plan justifying the ramp-up decision is of much relevance.

- Anticipating technical issues in the pre-ramp-up phase. As discussed with Company B, the tests and prototypes of series manufacturing in the pre-ramp-up phase help the industrials make better projections on their needs of material and human resources. It is also a mean of anticipating technical issues that can occur on a big scale by tackling them on a reduced prototype scale.

- Flexibility of the processes. When starting from scratch for the launch of a new product, a new process is also introduced. However, the discussion with Company B has shown that this process needs to fit into the existing value chain present in the company (current machinery available) but also that it should require the least investment when it comes to training the workforce.

- Adapting to employees' needs. It is clear that one major aspect of ramp-up management is the workforce. Consequently, it is natural that the company needs to prepare its employees for change management or for learning new skills that will be needed for the ramp-up phase. In the case of Company $\mathrm{B}$, a lesson of the covid-19 sanitary crisis would be to consider the employees' preferences regarding remote work or in-site presence and try to satisfy them when it's possible.

- Underestimating the cost of ramp-up entails a highly critical risk. Before launching the actual ramp-up phase, it seems just as important during the pre-ramp-up phase to work precisely on the projections of the business plan in terms of profit but also regarding the cost plan. This anticipation (over estimation) of the costs of ramp-up prevents the company from the risk of encountering additional unexpected costs during the journey of ramp-up in terms of quality and time. During the interview with Company $\mathrm{B}$, the technical risks that were pointed out are an example of these costs that need to be anticipated rather than endured.

- Having a limited panel of suppliers. In some fields like additive manufacturing, there is a limited number of suppliers as the processes may completely change from one project to another. However, one thing to do is to always try and have as large as possible of a suppliers' panel in order to be well equipped to face shortage of raw materials supply but also to have the choice regarding the cost of sourcing.

\section{Discussion and perspectives}

Shorter product lifecycles and the rising complexity of new products and processes led to a greater importance of ramp-up management in production. As the degree of product innovation also rises, there is a rapid rise in the total number of complex production ramp-ups and coordination of ramp-up activities becomes part of everyday business. The sanitary crisis unveiled the limitations of current ramp-up practices in the manufacturing and service industries to ensure agility and resilience. Innovative approaches are then needed to ensure quick and efficient ramp-up meeting individual and global demands. The current paper contributed towards this objective by an explorative research which examined the scientific literature and relied on interview to report on ramp-up practices considering the sanitary and sustainability objectives. The first results (set of guidelines) provided insights into how to deal with ramp-up management which are useful for decision makers in additive manufacturing and in cycling industry and beyond. Further research is ongoing in order to extend the results. For instance, the interviews that were conducted individually with local industrials have given us a good beginning in the path of looking for ramp-up management guidelines. However, two companies are not statistically a concluding sample. Therefore, we have decided to go from a qualitative approach of personalised interviews to a quantitative approach with a massive survey. The aim behind the launch of this survey will be to have it answered by industrial actors on a larger scale (both locally and internationally). The results of this survey will give an insight on how different countries, company sizes, fields of activity and the teams' organisation impacts the success or failure of ramp-up management. By the time this survey will be launched, it will also help have a more mature and fact-based opinion on the impact of the covid-19 crisis both on the production management and on ramp-up management; as well as the strategies that the companies would have developed to tackle this particular pandemic context. 


\section{Conclusion}

In this paper, we have assessed the current state of art on ramp-up management and identified guidelines for a successful ramp-up management. Specifically, we have started with the study of research findings in regard to ramp-up definitions, strategies, assessment KPIs. Moreover, this paper has exposed the best practices and no go identified after meeting with local companies and interviewing practitioners to establish ramp-up management guidelines.

\section{References}

1. Surbier, L., Alpan, G., Blanco, E.: A comparative study on production ramp-up: state-of-the-art and new challenges. Production Planning \& Control, 25(15), 1264-1286 (2014).

2. Terwiesch, C., Yi, X.: The copy-exactly ramp-up strategy: Trading-off learning with process change. Engineering Management, IEEE Transactions on, 51(1), 70 (2005).

3. Berg, M., Säfsten, K.: Managing Production Ramp-up- Requirement on strategy content, Department of Industrial Engineering and Management, Jönköping University, Sweden (2006).

4. Medini, K., Pierné, A., Erkoyuncu, J-A., Cornet, C.: A Model for Cost-Benefit Analysis of Production Rampup Strategies. In: Proceedings of the IFIP WG 5.7 International Conference (APMS 2020), pp. 731-739. Springer, Novi Sad, Serbia (2020).

5. Dombrowskia, U., Wullbrandta, J., Krenkela, P.: Industrie 4.0 in production ramp-up management. In: Proceedings of the $28^{\text {th }}$ International Conference on Flexible Automation and Intelligent Manufacturing, Procedia, Columbus, OH, USA (2018).

6. Slamanig, M., Winkler, H.: An exploration of ramp-up strategies in the area of mass customisation. International Journal of Mass Customisation, 4(1-2), 22-43 (2011).

7. Schuh, G., Desoi, J., Tücks, G.: Holistic Approach for Production Ramp-up in Automotive Industry. In: Advances in Integrated Design and Manufacturing in Mechanical Engineering, Bramley, A., Brissaud, D., Coutellier, D., McMahon, C. (Eds.) pp. 255-268. Berlin: Springer (2005).

8. Clark, K.B., Fujimoto, T.: Product development performance: Strategy, organization, and management in the world auto industry. HBS Press, Boston (1991). 